\title{
An Inventory Model with Partial Backordering, Weibull Distribution Deterioration under Two Level of Storage
}

\author{
Babita Taygi \\ Professor \\ Galgotia University \\ G. Nodia, U.P.
}

\author{
Ajay Singh \\ Yadav, PhD \\ Assistant Professor \\ SRM University \\ NCR Campus GZB
}

\author{
Sanjai Sharma \\ Research Scholar \\ Banasthali University \\ Jaipur, Rajasthan
}

\author{
Anupam Swami \\ Assistant Professor \\ Govt. P.G. College \\ Sambhal, U.P.
}

\begin{abstract}
This paper mainly presents a two warehouse inventory model for deteriorating items which follows the weibull deterioration rate under assumption that the deterioration rates are different in the both warehouses but deterioration cost is same in the both warehouses. The holding cost is variable and taken as linear function of time and demand is taken to be constant with the time. Salvages value is associated with the deteriorated units of inventories and Shortages are allowed in the OW and partially backlogged at the next replenishment cycle.
\end{abstract}

\section{Keywords}

Weibull distributed deterioration, partial backlogging, salvages value and Variable holding cost.

\section{INTRODUCTION}

Now days in the present market scenario of explosion of choice due to cut-throat competition, no company can bear a stock-out situation as a large number of alternative products are available with additional features. Furthermore, there is no cut-and- dried formula by means of which one can determine the demand exactly. Despite having considerable cost, firms have to keep an inventory of the various types of goods for their smooth functioning mainly due to geographical specialization, periodic variation and gap in demand and supply. When a firm needs an inventory, it must be stored in such a way that the physical attributes of inventory items can be preserved as well as protected. Thus, inventory produces the need for warehousing. Traditionally, a warehouse is typically viewed as a place where inventory items are stored. Warehouse is an essential limb of an industrial unit. In the existing literature, it was found that the classical inventory models generally deal with a single storage facility. The basic assumption in these models was that the management had storage with unlimited capacity. However, it is not true (e.g., in a supermarket, the storage space of showroom is very limited) in the field of inventory control. Due to attractive price discount during bulk purchase or some problems in frequent procurement or very high demand of items, management decides to purchase a huge quantity of items at a time. These items cannot be stored in the existing storage (owned warehouse, OW) with limited capacities. So, for storing the excess items, one (sometime more than one) warehouse is hired on rental basis. The rented warehouse RW is located near the OW or little away from it. Usually, the holding cost in RW is greater than the OW. Further, the items of RW are transported to OW, in bulk fashion to meet the customers demand until the stock level of RW is emptied. In the classical inventory models, found in the existing literature are that the life time of an item is infinite while it is in storage. But the effect of deterioration plays an important role in the storage of some commonly used physical goods like fruits, vegetables etc. In these cases, a certain fraction of these goods are either damaged or decayed and are not in a condition to satisfy the future demand of costumers as fresh units. Deterioration in these units is continuous in time and is normally proportional to on-hand inventory. Over a long time a good number of works have been done by some authors for controlling inventories in which a constant or a variable part of the on hand inventory gets deteriorated per unit of time. In many models it is assumed that the products are deteriorated constantly (i.e. deterioration rate is assumed to be constant) with time but in certain models, rate of deterioration taken probability dependent distribution rate i.e. deterioration depend on the quality of product i.e. some product deteriorated very fast and some are slow, so many researchers worked taking different probability distribution rate as the rate of deterioration. In general, in formulating inventory models, two factors of the problem have been of growing interest to the researchers, one being the deterioration of items and the other being the variation in the demand rate with time.Donaldson [1977] developed an optimal algorithm for solving classical no-shortage inventory model analytically with linear trend in demand over fixed time horizon. Dave, U. (1989) proposed a deterministic lot-size inventory model with shortages and a linear trend in demand. Goswami and Chaudhuri [1991]discussed different types of inventory models with linear trend in demand. Hariga (1995). Mandal and Maiti [1999] discussed an inventory of damageable items with variable replenishment rate and deterministic demand. Balkhi and Benkherouf [2004] developed an inventory model for deteriorating items with stock dependent and time varying demand rates over a finite planning horizon. Yang [2004] provided a two warehouse inventory model for a single item with constant demand and shortages under inflation. Zhou and Yang [2005] studied stock-dependent demand without shortage and deterioration with quantity based transportation cost. Wee et al. [2005] considered two-warehouse model with constant demand and weibull distribution deterioration under inflation. Mahapatra, N. K. and Maiti, M. [2005] presented the multi objective and single objective inventory models of stochastically deteriorating items are developed in which demand is a function of inventory level and selling price of the commodity. Panda et al. [2007] considered and EOQ model with ramp-type demand and Weibull distribution deterioration. Ghosh and Chakrabarty [2009] suggested an order-level inventory model with two levels of storage for deteriorating items. Sarala Pareek and Vinod Kumar [2009] developed a deterministic inventory model for deteriorating items with salvage value and shortages. Skouri, Konstantaras, Papachristos, and Ganas [2009] developed an inventory models with ramp type demand rate, partial backlogging and Weibell's deterioration rate. Mishra and Singh [2010] developed a deteriorating inventory model for waiting time partial backlogging when demand is time dependent and deterioration rate is constant. Kuo-Chen Hung [2011]gave an inventory model with generalized type demand, deterioration 
and backorder rates Mishra \& Singh [2011]developed a deteriorating inventory model for time dependent demand and holding cost with partial backlogging.Vinod Kumar Mishra [2012] made the paper of Sarala Pareek \& Vinod Kumar [2009] and Mishra \& Singh [2011] more realistic by considering that the salvage value is incorporated to the deteriorated items and holding cost is linear function of time and developed an inventory model for deteriorating items with time dependent deterioration rate in which demand rate is constant. Shortages are allowed and fully backlogged. Deteriorating items have salvage value.

Many authors have discussed Inventory model with single storage facility and Weibull distribution deterioration rate. An inventory model for a deteriorating item having two separate warehouses, one is an own warehouse (OW) and the other rented warehouse (RW) with Weibull deterioration rate has been considered and a rented warehouse is used when the ordering quantity exceeds the limited capacity of the owned warehouse. The holding costs at RW are higher than OW. In this study, it is assumed that the rate of deterioration in both warehouses is same as in the modern era the preservation facilities is the better in both warehouse and the holding cost was different and linearly depend on time. The demand rate is taken to be constant and shortages are allowed and partially backlogged. The aim of this model is to find an optimal order quantity and to minimize the total inventory cost. Numerical example will be presented to validate the model.

\section{ASSUMPTIONS AND NOTATION}

The mathematical model of the two-warehouse inventory problem is based on the following assumption and notations.

\subsection{Assumptions}

1. Demand rate is constant and known.

2. The lead time is zero or negligible and initial inventory level is zero.

3. The replenishment rate is infinite.

4. Shortages are allowed and partially backordered

5. Deterioration rate is time dependent and follows a two parameter weibull distribution where $\alpha>0$ denote scale parameter and $\beta>1$ denote the shape parameter.

6 . The salvage value $\gamma(0 \leq \gamma<1)$ is associated to deteriorated units during the cycle time.

7. The holding cost is a linear function of time and is higher in RW than OW.

8. The deteriorated units cannot be repaired or replaced during the period under review.

9. Deterioration occurs as soon as items are received into inventory.

\subsection{Notation}

The following notation is used throughout the paper:

$d$ Demand rate ( units/unit time ) which is constant

$W$ Capacity of OW

$\alpha$ Scale parameter of the deterioration rate in $\mathrm{OW}$ and $0<\alpha<1$

$\beta$ Shape parameter of the deterioration rate in OW and $\beta>0$. $\mu \quad$ Scale parameter of the deterioration rate in $\mathrm{RW}, \alpha>\mu$

$\eta \quad$ Shape parameter of the deterioration rate in $\mathrm{RW}$

$F \quad$ Fraction of the demand backordered during the stock out period

$C_{o} \quad$ Ordering cost per order

$\mathrm{C}_{\mathrm{d}}$ Deterioration cost per unit of deteriorated item in both ware-houses

$\mathrm{H}_{\mathrm{o}}=\mathrm{bt}_{1}$; Holding cost per unit per unit time in OW during

$T_{1}$ time period and $b>0$

$\mathrm{H}_{\mathrm{o}}=\mathrm{bt}_{2}$; Holding cost per unit per unit time in OW during

$T_{2}$ time period and $b>0$

$\mathrm{H}_{\mathrm{R}}=\mathrm{at}_{1}$; Holding cost per unit per unit time in RW during

$T_{1}$ time period such that $\mathrm{H}_{\mathrm{R}}>\mathrm{H}_{\mathrm{o}}$

$\mathrm{C}_{\mathrm{s}} \quad$ Shortage cost per unit per unit time

$\mathrm{L}_{\mathrm{c}} \quad$ Shortage cost for lost sales per unit

$\mathrm{Q}_{0}$ The order quantity in OW

$Q_{R}$ The order quantity in RW

$\mathrm{Q}_{\mathrm{M}}$ Maximum ordered quantity after a complete time period T

$I_{k} \quad$ Maximum inventory level in RW

$T_{1} \quad$ Time with positive inventory in RW

$T_{1}+T_{2}$ Time with positive inventory in OW

$T_{3}$ Time when shortage occurs in OW

$T$ Length of the cycle, $T=T_{1}+T_{2}+T_{3}$

$I_{i}^{O}(t i)$ Inventory level in OW at time $t i, 0 \leq t i \leq T i, i=1,2,3$

$I^{R}\left(t_{l}\right)$ Inventory level in RW at time $t_{l}, 0 \leq t_{1} \leq T_{1}$

$T_{C}^{I} \quad$ The present value of the total relevant inventory cost per unit time

The rate of deterioration is given as follows:

$t \quad$ Time to deterioration, $t>0$

Instantaneous rate of deterioration in OW

$Z(t)=\alpha \beta t^{\beta-1}$ where $0 \leq \alpha<1$

Instantaneous rate of deterioration in RW

$\mathrm{R}(\mathrm{t})=\eta \eta t^{\eta-1}$ where $\eta>0$,

\section{MATHEMATICAL DEVELOPMENT OF MODEL}

Figure-1,representing Own Ware-House Inventory System can be divided into three part depicted by $T_{1}, T_{2}$ and $T_{3}$. For each replenishment a portion of the replenished quantity is used to backlog shortage, while the rest enters into the system. $W$ units of items are stored in the OW and the rest is kept into the $\mathrm{RW}$. The inventory level in RW inventory system has been depicted graphically in Figure-2.The inventory in RW is supplied first to reduce the inventory cost due to more holding cost as compared to OW. Stock in the RW during time interval $\mathrm{T}_{1}$ depletes due to demand and deterioration until it 
reaches zero. During the time interval, the inventory in OW decreases due to deterioration only. The stock in OW depletes due to the combined effect of demand and deterioration during time $\mathrm{T}_{2}$. During the time

interval $T_{3}$, both warehouses are empty, and part of the shortage is backordered in the next replenishment.
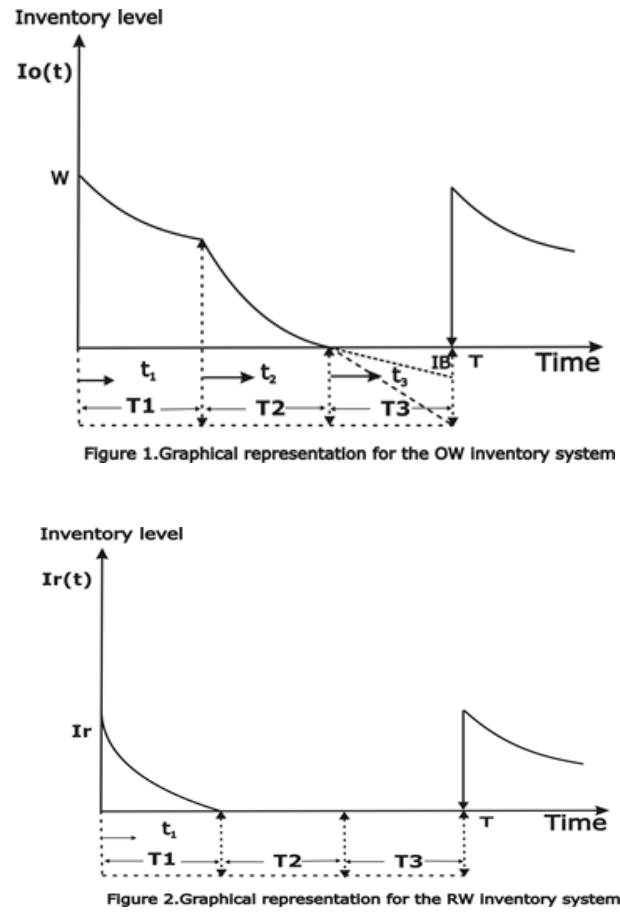

The rate of change of inventory during positive stock in RW and time period $T_{1}$ can be represented by the differential equation

$\frac{d I^{R}\left(t_{1}\right)}{d t_{1}}=-? \eta t_{1}^{\eta-1} I^{R}\left(t_{1}\right)-\mathrm{d} \quad ; \quad 0 \leq t_{1} \leq \mathrm{T}_{1}$

Solution of above equation with B.C. $I^{R}(0)=I^{r}$ is

$I^{R 1}\left(t_{1}\right)=\left(I^{r}-\mathrm{d} \int_{0}^{t_{1}} e^{\varpi u^{\eta}} \mathrm{du}\right) e^{-\varpi t_{1}^{\eta}} ; 0 \leq t_{1} \leq \mathrm{T}_{1}$

Where $I^{r}=\mathrm{d} \int_{0}^{T_{1}} e^{\square u^{\eta}} \mathrm{du}=\mathrm{d} \sum_{m=0}^{\infty} \frac{\mu^{m} T_{1}^{m \eta+1}}{m !(m \eta+1)}$

$$
\approx \mathrm{d}\left(T_{1}+\frac{\mu T_{1}^{\eta+1}}{\eta+1}\right)
$$

The rate of change of inventory during positive stock in OW and time period $\mathrm{T}_{1}+\mathrm{T}_{2}+\mathrm{T}_{3}$ can be represented by the following differential equation

$\begin{array}{ll}\frac{d I_{1}^{O}\left(t_{1}\right)}{d t_{1}}=-\alpha \beta t_{1}^{\beta-1} I_{1}^{O}\left(t_{1}\right) ; & 0 \leq t_{1} \leq \mathrm{T}_{1} \\ \frac{d I_{2}^{O}\left(t_{2}\right)}{d t_{2}}=-\alpha \beta t_{1}^{\beta-1} I_{2}^{O}\left(t_{2}\right)-\mathrm{d} ; & 0 \leq t_{2} \leq \mathrm{T}_{2}\end{array}$

Shortages starts during the stock out time period $\mathrm{T}_{3}$ in OW and can be represented by the differential equation

$\frac{d I_{3}^{O}\left(t_{3}\right)}{d t_{3}}=-\mathrm{Fd} ; \quad 0 \leq t_{3} \leq \mathrm{T}_{3}$

Solution of above differential equation with boundary conditions, $I_{1}^{O}(0)=\mathrm{W}, I_{1}^{O}\left(T_{1}\right)=\mathrm{W} e^{-\alpha T_{1}^{\beta}}=I_{2}^{O}(0)$ and $I_{3}^{O}(0)=0$ can be given as

$I_{1}^{O}\left(t_{1}\right)=\mathrm{W} e^{-\alpha t_{1}^{\beta}} ; \quad 0 \leq t_{1} \leq \mathrm{T}_{1}$

$$
\begin{aligned}
& I_{2}^{O}\left(t_{2}\right)=\left(\mathrm{W} e^{-\alpha T_{1}^{\beta}}-\mathrm{d} \int_{0}^{t_{2}} e^{\alpha u^{\beta}} \mathrm{du}\right) e^{-\alpha t_{2}^{\beta}} ; 0 \leq t_{2} \leq \mathrm{T}_{2} \\
& I_{3}^{O}\left(t_{3}\right)=-\mathrm{Fdt}_{3} ; \quad 0 \leq t_{3} \leq \mathrm{T}_{3}
\end{aligned}
$$

The amount of inventory deteriorated during time period $\mathrm{T}_{1}$ in $\mathrm{RW}$ is denoted and given as

$\mathrm{D}^{\mathrm{R}}=\int_{0}^{T_{1}} \mathrm{R}(\mathrm{t}) \mathrm{I}^{\mathrm{R}} \mathrm{dt}_{1}$
$=\mu \mathrm{d}\left(T_{1}+\frac{\mu T_{1}^{\eta+1}}{\eta+1}\right) T_{1}^{\eta} \approx \mu \mathrm{d} T_{1}^{\eta+1}$

Cost of deteriorated items in RW is denoted and given as

$\mathrm{CD}^{\mathrm{R}}=\mathrm{C}_{\mathrm{d}} \mu \mathrm{d} T_{1}^{\eta+1}$

The amount of inventory deteriorated during time period $\mathrm{T}_{1}+\mathrm{T}_{2}$ in $\mathrm{OW}$ is denoted and given as

$\mathrm{D}^{\mathrm{O}}=\int_{0}^{T_{1}} \mathrm{Z}(\mathrm{t}) W d t_{1}+\left(\mathrm{W} e^{-\alpha T_{1}^{\beta}}-\int_{0}^{T_{2}} d d t_{2}\right)$

$=\mathrm{W}\left(\alpha T_{1}^{\beta}+e^{-\alpha T_{1}^{\beta}}\right)-\mathrm{dT}_{2}$

(3.12)

Cost of deteriorated items in OW is denoted and given as

$\mathrm{CD}^{\mathrm{O}}=\mathrm{C}_{\mathrm{d}}\left\{\mathrm{W}\left(\alpha T_{1}^{\beta}+e^{-\alpha T_{1}^{\beta}}\right)-\mathrm{dT}_{2}\right\}$

The maximum ordered quantity is denoted and given as

$\mathrm{M}_{\mathrm{Q}}=\mathrm{d}\left(T_{1}+\frac{\mu T_{1}^{\eta+1}}{\eta+1}\right)+\mathrm{W}+F d \frac{T_{3}^{2}}{2}$

The inventory holding cost in OW during time period $\mathrm{T}_{1}+\mathrm{T}_{2}$ is denoted by $\mathrm{IH}^{\mathrm{O}}$ and given as

$$
\begin{aligned}
\mathrm{IH}^{\mathrm{O}}= & \int_{0}^{T_{1}} H_{O} I_{1}^{O}\left(t_{1}\right) d t_{1}+\int_{0}^{T_{2}} H_{O} I_{2}^{O}\left(t_{2}\right) d t_{2} \\
= & {\left[b W\left\{\frac{T_{1}^{2}}{2}-\frac{\alpha T_{1}^{\beta+2}}{\beta+2}\right\}+b W\left\{\frac{T_{2}^{2}}{2}\left(1-\alpha T_{1}^{\beta}\right)-\frac{\alpha T_{2}^{\beta+2}}{\beta+2}\right\}-\right.} \\
& \left.b d\left\{\frac{T_{2}^{3}}{3}-\frac{\alpha \beta T_{2}^{\beta+3}}{(\beta+1)(\beta+3}\right\}\right]
\end{aligned}
$$

Shortages occurs during time period $\mathrm{T}_{3}$ due to non-availability of stock in $\mathrm{OW}$, which is denoted by $\mathrm{S}_{\mathrm{H}}$ and can be given as follows

$\mathrm{S}_{\mathrm{H}}=\int_{0}^{T_{3}}\left\{-I_{3}^{O}\left(t_{3}\right)\right\} d t_{3}$

$=F d \frac{T_{3}^{2}}{2}$

Shortages cost of inventory short is denoted and given as

$\mathrm{CS}_{\mathrm{H}}=\mathrm{C}_{\mathrm{S}} F d \frac{T_{3}^{2}}{2}$

Lost sales occurs during shortages period in OW due to partial backlogging and the amount of sale lost is denoted by $\mathrm{L}_{\mathrm{S}}$ and given as follows

$$
\begin{aligned}
\mathrm{L}_{\mathrm{S}} & =\int_{0}^{T_{3}}(1-F) d d t_{3} \\
& =(1-F) d \mathrm{~T}_{3}
\end{aligned}
$$

Cost of lost sales is denoted by $\mathrm{CL}_{\mathrm{S}}$ and is given as

$\mathrm{CL}_{\mathrm{S}}=\mathrm{L}_{\mathrm{S}}(1-F) d \mathrm{~T}_{3}$

The inventory holding cost in RW during time period $\mathrm{T}_{1}$ is denoted by $\mathrm{IH}^{\mathrm{R}}$ and given as 
$\mathrm{IH}^{\mathrm{R}}=\int_{0}^{T_{1}} a t_{1} I^{R}\left(t_{1}\right) d t_{1}$

$=a d\left\{\frac{T_{1}^{3}}{6}+\frac{\square \eta T_{1}^{\eta+3}}{2(\eta+2)(\eta+3)}\right\}$

The salvages cost of deteriorated units per unit time is denoted by SV and given as

$\mathrm{SV}=\gamma\left[\mu \mathrm{d} T_{1}^{\eta+1}+\mathrm{W}\left(\alpha T_{1}^{\beta}+e^{-\alpha T_{1}^{\beta}}\right)-\mathrm{dT}_{2}\right]$

The present value of the total inventory cost during the cycle denoted by $\mathrm{T}_{\mathrm{C}}^{\mathrm{I}}$ is the sum of ordering cost (OC) per cycle, the inventory holding cost $\left(\mathrm{IH}^{\mathrm{R}}\right)$ per cycle in $\mathrm{RW}$, the inventory holding $\left(\mathrm{IH}^{\mathrm{O}}\right)$ per cycle in OW, Deterioration cost per cycle in $\mathrm{RW}$, Deterioration cost per cycle in OW, the shortages cost $\left(\mathrm{CS}_{\mathrm{H}}\right)$ in $\mathrm{OW}$, the lost sales cost (CLS) and minus the salvages value of deteriorated units i.e.

$\mathrm{T}_{\mathrm{C}}^{\mathrm{I}}\left(\mathrm{T}_{1}, \mathrm{~T}_{2} \quad, \mathrm{~T}_{3}\right)=\frac{1}{T}\left[\mathrm{OC}+\mathrm{IH}^{\mathrm{R}}+\mathrm{IH}^{\mathrm{O}}+\mathrm{CD}^{\mathrm{R}}+\mathrm{CD}^{\mathrm{O}}+\mathrm{CS}_{\mathrm{H}}+\right.$ $\left.\mathrm{C} L_{S}-\mathrm{SV}\right]$

$=\frac{1}{T}\left[O_{c}+a d\left\{\frac{T_{1}^{3}}{6}+\frac{\square \eta T_{1}^{\eta+3}}{2(\eta+2)(\eta+3)}\right\}+\left[\mathrm{bW}\left\{\frac{T_{1}^{2}}{2}-\frac{\alpha T_{1}^{\beta+2}}{\beta+2}\right\}+\right.\right.$ $\left.\mathrm{bW}\left\{\frac{T_{2}^{2}}{2}\left(1-\alpha T_{1}^{\beta}\right)-\frac{\alpha T_{2}^{\beta+2}}{\beta+2}\right\}-b d\left\{\frac{T_{2}^{3}}{3}-\frac{\alpha \beta T_{2}^{\beta+3}}{(\beta+1)(\beta+3)}\right\}\right]+$ $C_{d} \mu \mathrm{d} T_{1}^{\eta+1}+C_{d}\left\{\mathrm{~W}\left(\alpha T_{1}^{\beta}+e^{-\alpha T_{1}^{\beta}}\right)-\mathrm{dT}_{2}\right\}+C_{S} F d \frac{T_{3}^{2}}{2}+$

$\left.L_{S}(1-F) d \mathrm{~T}_{3}-\gamma\left[\mu \mathrm{d} T_{1}^{\eta+1}+\mathrm{W}\left(\alpha T_{1}^{\beta}+e^{-\alpha T_{1}^{\beta}}\right)-\mathrm{dT}_{2}\right]\right]$

The optimal problem can be formulated as

Minimize: $\mathrm{T}_{\mathrm{C}}^{\mathrm{I}}\left(\mathrm{T}_{1}, \mathrm{~T}_{2}, \mathrm{~T}_{3}\right)$

Subject to: $\mathrm{T}_{1} \geq 0, \mathrm{~T}_{2} \geq 0, \mathrm{~T}_{3} \geq 0$

To find the optimal solution of the equation the following condition must be satisfied

$\frac{\partial \mathrm{T}_{\mathrm{C}}^{\mathrm{I}}\left(T_{1}, T_{2}, T_{3}\right)}{\partial T_{1}}=0 ; \quad \frac{\partial \mathrm{T}_{\mathrm{C}}^{\mathrm{I}}\left(T_{1}, T_{2}, T_{3}\right)}{\partial T_{2}}=0 ; \quad \frac{\partial \mathrm{T}_{\mathrm{C}}^{\mathrm{I}}\left(T_{1}, T_{2}, T_{3}\right)}{\partial T_{3}}=0$

Solving equation (1.22) respectively for $T_{1}, T_{2}, T_{3}$, we can obtain $\check{\mathrm{T}}_{1}, \check{\mathrm{T}}_{2}, \breve{\mathrm{T}}_{3}, \mathrm{~T}^{*}$ and with these values we can find the total minimum inventory cost from equation (3.22).

\section{ONE WARE HOUSE SYSTEM}

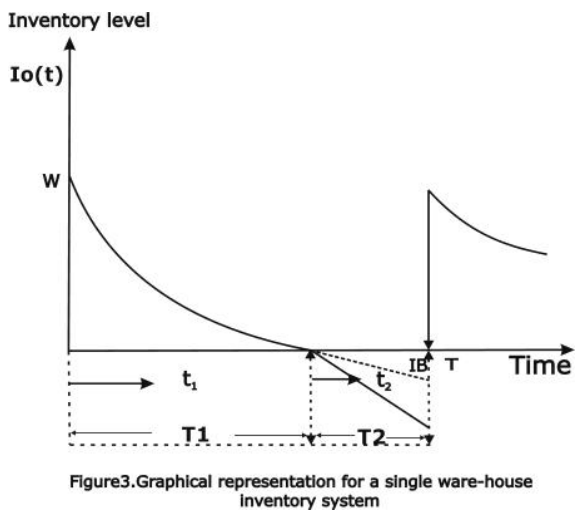

Figure shows the graphical representation of one ware-house inventory system. Now considering the one warehouse inventory system we derive the inventory level during time periods $T_{1}$ and $T_{2}$ which are represented by differential equation

$\frac{d I_{1}^{o}\left(t_{1}\right)}{d t_{1}}=-\alpha \beta \mathrm{t}_{1}^{\beta-1} \mathrm{~W}-\mathrm{d} ; \quad 0 \leq \mathrm{t}_{1} \leq \mathrm{T}_{1}$

Solution of above differential equation with boundary conditions, $I_{1}^{O}(0)=\mathrm{W}$

$I_{1}^{O}\left(t_{1}\right)=\mathrm{W}\left(1-\alpha \mathrm{t}_{1}^{\beta}\right)-\mathrm{dt}_{1} ; 0 \leq \mathrm{t}_{1} \leq \mathrm{T}_{1}$

Shortages occur during the time period $\left[\begin{array}{ll}0 & \mathrm{~T}_{2}\end{array}\right]$.The present worth shortages cost is

$$
\begin{gathered}
\mathrm{S}_{\mathrm{C}}=\mathrm{C}_{\mathrm{S}}\left\{\int_{0}^{T_{2}}\left(F d t_{2}\right) d t_{2}\right. \\
=\frac{\mathrm{C}_{\mathrm{s}} \mathrm{Fd}}{2} \mathrm{~T}_{2}^{2}
\end{gathered}
$$

Loss of sales occur during $\mathrm{T}_{2}$ time period .The OW present worth lost sales cost is given as

$\mathrm{CL}_{\mathrm{S}}=\mathrm{L}_{\mathrm{S}} \quad\left\{\int_{0}^{T_{2}}(1-F) d d t_{2}\right\}$

$$
=\mathrm{L}_{\mathrm{C}}(1-\mathrm{F}) \mathrm{d} \mathrm{T}_{2}
$$

Cost of deteriorated units in time interval $\left[0 \mathrm{~T}_{1}\right]$ is given as

$\mathrm{CD}^{\mathrm{R}}=\mathrm{C}_{\mathrm{d}} \alpha \mathrm{W} \mathrm{d} \mathrm{\textrm {T } _ { 1 } ^ { \beta }}$

The Maximum order quantity per order is

$\mathrm{M}_{\mathrm{Q}}=\mathrm{W}+\frac{\mathrm{Fd}}{2} \mathrm{~T}_{2}^{2}$

Salvages value of deteriorated units per unit time is

$\mathrm{SV}=\gamma \mathrm{W} \alpha T_{1}^{\beta}$

Inventory holding cost during time period $\mathrm{T}_{1}$ is

$$
\begin{gathered}
\mathrm{IH}^{\mathrm{O}}=\int_{0}^{T_{1}} H_{O} I_{1}^{O}\left(t_{1}\right) d t_{1} \\
=b W\left\{\frac{T_{1}^{2}}{2}-\frac{\alpha T_{1}^{\beta+2}}{\beta+2}\right\}
\end{gathered}
$$

Noting that $\mathrm{T}=\mathrm{T}_{1}+\mathrm{T}_{2}$, the total present value of the total relevant cost per unit time during the cycle is the sum of the ordering cost ,holding cost shortages cost ,lost sales cost minus salvages value of deteriorated units i.e.

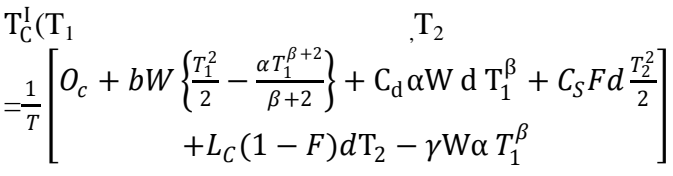

The optimal problem can be formulated as

Minimize: $\mathrm{T}_{\mathrm{C}}^{\mathrm{I}}\left(\mathrm{T}_{1}, \mathrm{~T}_{2}\right)$

Subject to: $\mathrm{T}_{1} \geq 0, \mathrm{~T}_{2} \geq 0$;

To find the optimal solution of the equation the following condition must be satisfied

$\frac{\partial \mathrm{T}_{\mathrm{C}}^{\mathrm{I}}\left(T_{1}, T_{2}\right)}{\partial T_{1}}=0 ; \quad \frac{\partial \mathrm{T}_{\mathrm{C}}^{\mathrm{I}}\left(T_{1}, T_{2}\right)}{\partial T_{2}}=0 ;$

\section{NUMERICAL EXAMPLE}

The Optimal replenishment policy to minimize the total present value inventory cost is derived by using the methodology given in the preceding section. The following set of parameters is assumed to analyse and validate the model 
The values of parameter should be taken in a proper unit. The fixed values of set $\left\{\mathrm{a}, \mathrm{b}, \mathrm{C}, \mathrm{C}_{\mathrm{d}} \mathrm{Cs}, \mathrm{L}_{\mathrm{s}}, \mathrm{F}, \alpha, \beta, \mu, \eta, \mathrm{d}, \mathrm{W}, \gamma\right\}$ taken as $\{25,20,100,10,25,10,0.8,0.05,1.8,1.8,0.02,400,100,8\} . \quad W e$ have computed the value of decision variables using equations 3.23 and 4.9 for the two models and then the value of inventory cost for the corresponding model is calculated using equations 3.22 and 4.8. The computational results are shown in table-1.

\subsection{Numerical results}

The decision variable so obtained for the models are as follows:

Table-1

\begin{tabular}{|c|c|c|}
\hline $\begin{array}{c}\text { Decision } \\
\text { Variables }\end{array}$ & $\begin{array}{c}\text { Value obtained for } \\
\text { Two Ware-house } \\
\text { model }\end{array}$ & $\begin{array}{c}\text { Value obtained for } \\
\text { One Ware-house } \\
\text { system }\end{array}$ \\
\hline$\check{\mathrm{T}}_{1}$ & 0.4003150 & 0.0426341 \\
\hline$\check{\mathrm{T}}_{2}$ & 3.5014900 & 0.0426341 \\
\hline$\check{\mathrm{T}}_{3}$ & 0.0859854 & ---------- \\
\hline $\mathrm{T}^{*}$ & 3.9877904 & 0.1668881 \\
\hline $\mathrm{T}_{\mathrm{C}}^{\mathrm{I}}$ & 1487.8800 & 1794.0300 \\
\hline
\end{tabular}

We conclude from the above numerical result as follows

1.From table-1, when all the given conditions and constraints are satisfied, the optimal solution is obtained. In this example the minimal present value of total relevant inventory cost per unit time in an appropriate unit is 1487.88 , while the respective optimal values of decision variables $\breve{\mathrm{T}} 1, \breve{\mathrm{T}} 2$, $\breve{\mathrm{T}} 3$ and $\mathrm{T}^{*}$ are $0.4003150,3.5014900,0.0859854$ and 3.9877904 respectively.

2. When there is only single ware-house with limited capacity $\mathrm{W}$ units is considered then the minimal present value of total relevant inventory cost per unit time in an appropriate unit is 1794.03 while the respective optimal time period of positive and negative inventory level are $0.0426341,0.0426341$ and 0.1668881 respectively. The total relevant inventory cost incurs an increase of 306.15 as compared with two warehouse system. The system has no space to store excess units and the total relevant inventory cost is higher due to holding cost and shortages cost.

3. When there is complete backlogging (i.e. $\mathrm{F}=1$ ), the minimal value of the total relevant inventory cost is 2122.66 while the respective values of decision variables $\check{\mathrm{T}}_{1}, \check{\mathrm{T}}_{2}, \breve{\mathrm{T}}_{3}$ and $\mathrm{T}^{*}$ are $6.65684,1.78748,0.212266$ and 8.656586 respectively. The total relevant inventory cost incurs an increase of 634.78 as compared to partial backlogging model under two ware-house systems.

4. The graphical representation of convex in Figure-4 for the total relevant inventory cost in the two ware-house system and in Figure-5 for the total relevant inventory cost in the one ware-house system shows that there exist a point where the total relevant inventory cost is minimum.

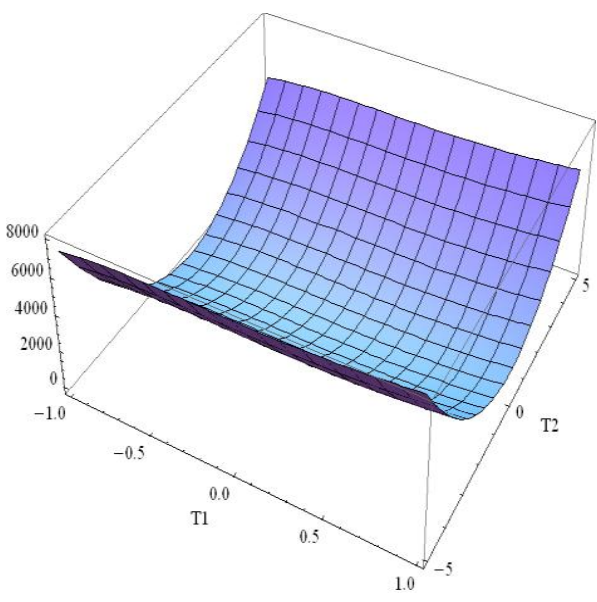

Figure-4 Graphical representation of $T_{C}^{I *}\left(\right.$ When $\check{T}_{3} *=$ $\mathbf{0 . 0 8 5 9 8 5 4}$ ) for Two ware-house system

\section{SENSITIVITY ANALYSIS}

In order to study the effects of parameters after the optimal solution. Sensitivity analysis is performed for the numerical example given at point 6.0 , we found that the optimal values of $\breve{\mathrm{T}}_{1} \quad \breve{\mathrm{T}}_{2}, \breve{\mathrm{T}}_{3}$ and $\mathrm{T}_{\mathrm{C}}^{\mathrm{I} *}$. For a fixed subset $\mathrm{S}=\left\{\mathrm{a}, \mathrm{b}, \mathrm{C}, \mathrm{C}_{\mathrm{d}}, \mathrm{Cs}, \mathrm{L}_{\mathrm{s}}, \mathrm{F}, \alpha, \beta, \mu, \mathrm{y}, \mathrm{d}, \mathrm{W}, \gamma\right\}$.The base column of $\mathrm{S}$ is $\mathrm{S}=\{25,20,100,10,25,10,0.8,0.05,1.8,1.8,0.02,400,100,8\}$. The optimal values of $\breve{\mathrm{T}}_{1 *} \breve{\mathrm{T}}_{2 *} \breve{\mathrm{T}}_{3 *}$ andT $\mathrm{C}$ are derived when one of the parameters in the subset $\mathrm{S}$ increases by $10 \%$ and all other parameters remain unchanged. The result of the sensitivity analysis are shown in the Table-2 with corresponding graphical representation. The change in the total relevant inventory cost given as percentage Change in Cost $(\mathrm{PCC})$ is as PCC $=\frac{\mathrm{T}_{C}^{\mathrm{IC}}-\mathrm{T}_{C}^{\mathrm{I} *}}{\mathrm{~T}_{\mathrm{C}}^{\mathrm{I*}}} \times 100$

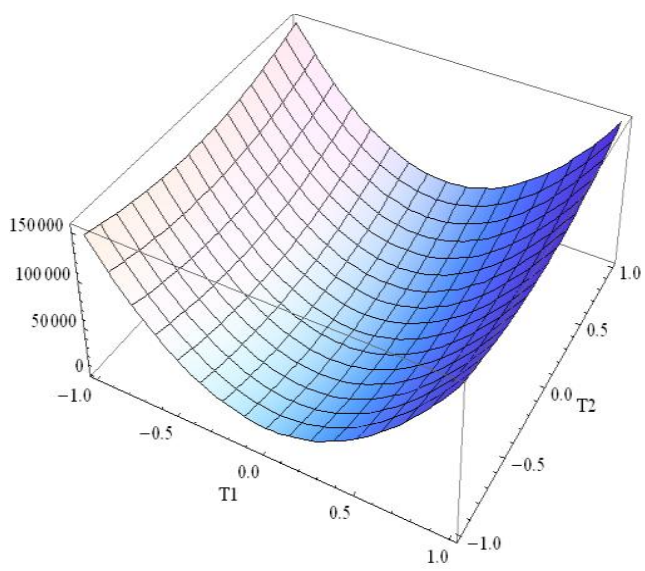

Figure-5. Graphical representation convex of $T_{C}^{I *}$ for Oneware-house system

Table-2. Sensitivity analysis when the parameter is changed by $10 \%$

\begin{tabular}{|c|c|c|c|c|c|c|c|}
\hline A & $\check{\mathrm{T}}_{1 *}$ & $\check{\mathrm{T}}_{2^{*}}$ & $\check{\mathrm{T}}_{3 *}$ & $\mathrm{~T}_{\mathrm{C}}^{\mathrm{IC}}$ & $\operatorname{PCC}(\%)$ & \multirow{2}{*}{$\begin{array}{c}\mathrm{PCC} \\
0.2\end{array}$} & \multirow{5}{*}{$\square$ changed } \\
\hline 30 & 0.3732 & 3.4991 & 0.0866 & 1492.72 & 0.32 & & \\
\hline 27.5 & 0.3859 & 3.5002 & 0.0863 & 1490.43 & 0.17 & \multirow{3}{*}{$\begin{array}{l}0.2 \\
0.4 \\
0.6 \\
0.8\end{array}$} & \\
\hline 22.5 & 0.4169 & 3.5029 & 0.0856 & 1485.08 & -0.19 & & \\
\hline 20 & 0.4362 & 3.6668 & 0.0853 & 1475.85 & -0.80 & & \\
\hline
\end{tabular}




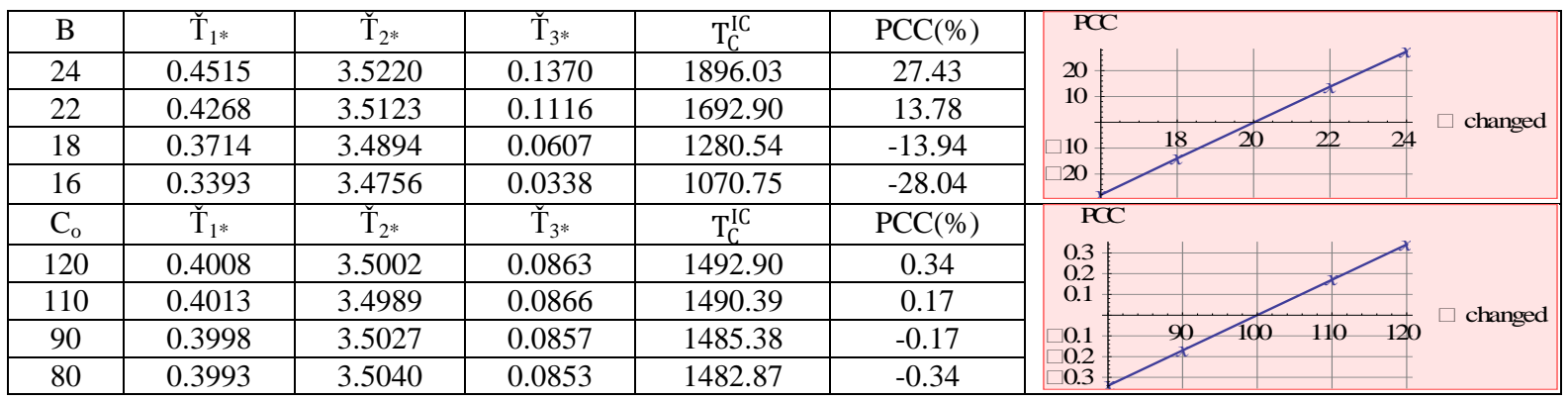

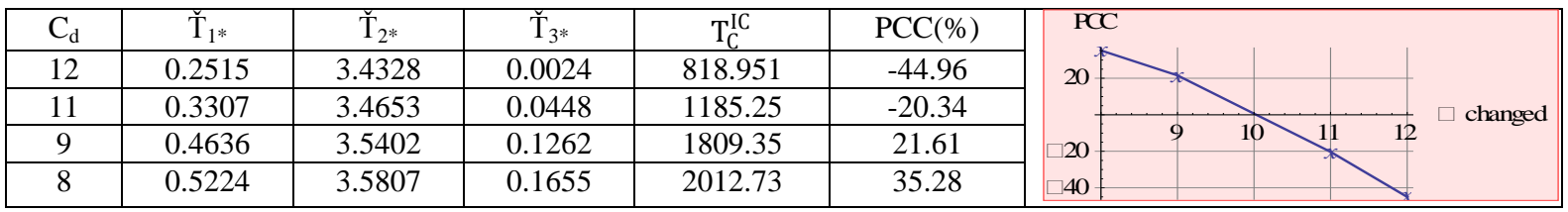

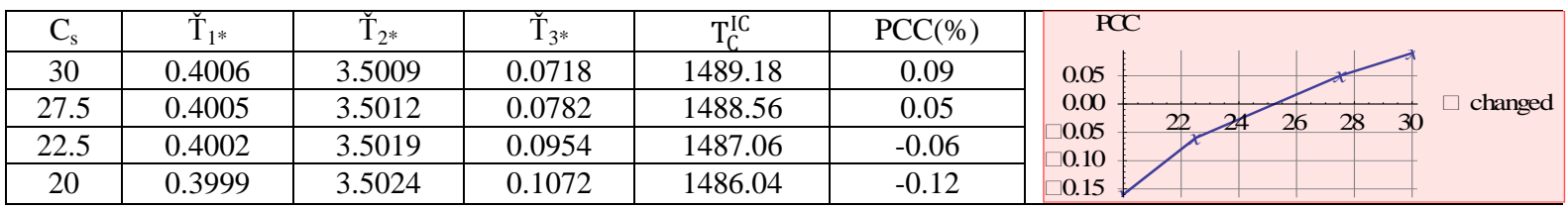

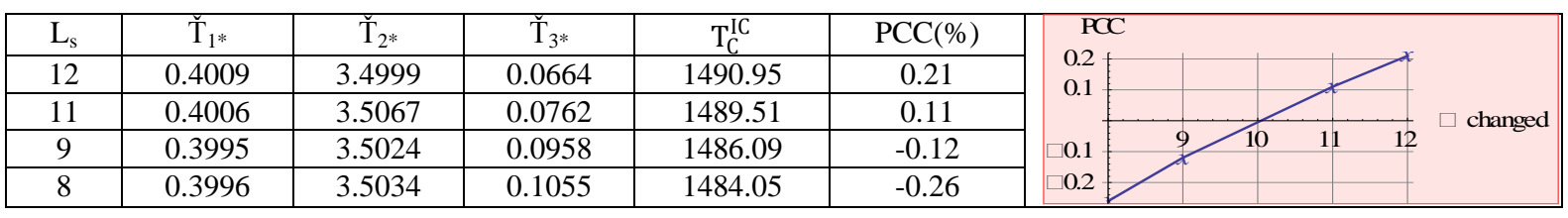

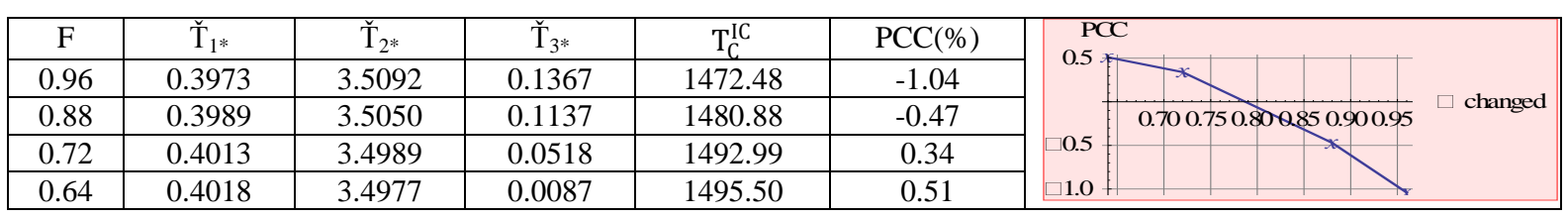

\begin{tabular}{|c|c|c|c|c|c|c|c|}
\hline$\alpha$ & $\check{\mathrm{T}}_{1 *}$ & $\check{\mathrm{T}}_{2^{*}}$ & $\check{\mathrm{T}}_{3 *}$ & $\mathrm{~T}_{\mathrm{C}}^{\mathrm{IC}}$ & $\mathrm{PCC}(\%)$ & \multicolumn{2}{|c|}{$\mathrm{PCC}$} \\
\hline 0.060 & 0.3653 & 3.1908 & 0.0644 & 1315.15 & -11.61 & $\begin{array}{l}15 \\
10\end{array}$ & \\
\hline 0.055 & 0.3818 & 3.3357 & 0.0744 & 1395.59 & -6.20 & 5 & \\
\hline 0.045 & 0.4215 & 3.6935 & 0.0940 & 1595.21 & 7.21 & $\square 5$ & $0.045 \quad 0.050 \quad 0055 \quad 0.060 \quad \square$ changed \\
\hline 0.040 & 0.4459 & 3.9198 & 0.1153 & 1722.08 & 15.74 & $\square 10$ & 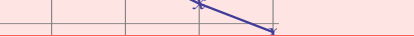 \\
\hline
\end{tabular}

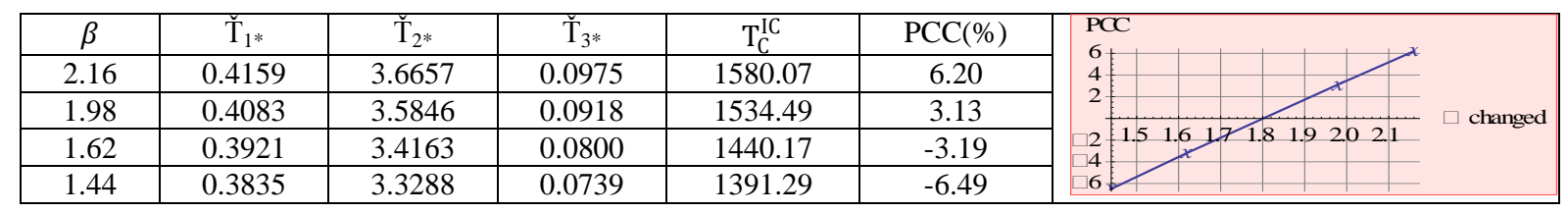

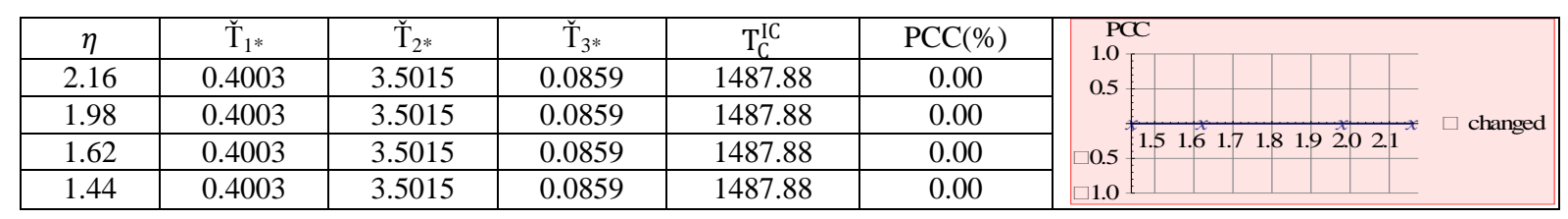

\begin{tabular}{|c|c|c|c|c|c|c|c|}
\hline$\mu$ & $\check{\mathrm{T}}_{1 *}$ & $\check{\mathrm{T}}_{2 *}$ & $\check{\mathrm{T}}_{3 *}$ & $\mathrm{~T}_{\mathrm{C}}^{\mathrm{IC}}$ & $\operatorname{PCC}(\%)$ & \multicolumn{2}{|c|}{$\begin{array}{l}\text { PCC } \\
0.02\end{array}$} \\
\hline 0.024 & 0.3997 & 3.5013 & 0.0806 & 1488.20 & 0.02 & 0.01 & \\
\hline 0.022 & 0.4000 & 3.5014 & 0.0860 & 1488.04 & 0.01 & 0.00 & $\square$ change \\
\hline 0.018 & 0.4006 & 3.5016 & 0.0859 & 1487.72 & -0.01 & $\square 0.01$ & 120.04 \\
\hline 0.016 & 0.4009 & 3.5017 & 0.0859 & 1487.56 & -0.02 & $\square 0.02$ & \\
\hline
\end{tabular}


[11] Skouri, K., I. Konstantaras, S. Papachristos, and I. Ganas, [2009]. Inventory models with ramp type demand rate, partial backlogging and Weibull deterioration rate. European Journal of Operational Research. European Journal of Operational Research, 192, 79-92.

[12] V. Mishra \& L. Singh,[2011]. Deteriorating inventory model for time dependent demand and holding cost with partial backlogging. International Journal of Management Science and Engineering Management, X(X): 1-5, 2011

[13] Vinod Kumar Mishra,[2012],Inventory Model for Time Dependent Holding Cost and Deterioration with Salvage value and Shortages ,TJMCS Vol. 4 No. 1 (2012) 37 47.

[14] Ajay Singh Yadav, Anupam Swami [2013], A TwoWarehouse Inventory Model for Decaying Items with Exponential Demand and Variable Holding Cost, International Journal of Inventive Engineering and Sciences (IJIES) ISSN: 2319-9598, Volume-1, Issue-5, April 2013.

[15] Hui-Ming Wee, Jonas C.P. Yu and S. T. Law [2005],Two -ware house Inventory model with Partial backordering and Weibull Distribution Deterioration under Inflation, JCIIE,Vol. 22 No-6,pp 451-462. 